\title{
Neck Metastasis Mimicking Abscess
}

\author{
Omar Ramadan* \\ Department of ENT, USA \\ Submission: January 4, 2017; Published: January 06, 2017 \\ *Corresponding author: Omar Ramadan, Independent researcher, ENT registrar, Paterson NJ, USA
}

Abbreviations: IL: Interleukin; VEGF: Vascular Endothelial Growth Factor; HNSCCs: Human Head and Neck Squamous Cell Carcinomas

\section{Case Report}

A 35-year-old woman was referred to the emergency department with a swelling and pain in the left submandibular area. Her symptoms started two weeks prior her presentation. On physical examination, there was a $3 \times 4 \mathrm{~cm}$ fluctuating mass in left submandibular area, the skin over the mass was erythermatous, there was also a vegetative mass measuring $2 \times 2 \mathrm{~cm}$ in the left buccal mucosa. A provisional diagnosis of abscess was considered. A neck CT examination revealed multiple hypodense lesions with marked peripheral contrast enhancement in left submandibular area, the biggest one measuring $3 \times 3 \mathrm{~cm}$. submandibular gland was intact. Biopsy was taken from buccal lesion and aspiration was done for the submandibular mass. Aspiration results revealed SCC cells and buccal biopsy result was SCC.

In laboratory and experimental studies there is great evidence about the role of inflammation in head and neck cancers. Ondrey et al. [1] reported that head and neck squamous cell carcinomas may express the pro-inflammatory and proangiogenic cytokines interleukin (IL)-1 $\alpha$, IL-6, IL-8, and granulocyte-macrophage colony-stimulating factor in vitro and in vivo. Bancroft et al. [2] indicated that Interleukin 8 (IL-8) and vascular endothelial growth factor (VEGF) promote tumor angiogenesis, growth, and metastasis and are co expressed by human head and neck squamous cell carcinomas (HNSCCs) and a variety of other cancers. Jackson-Bernitsas et al. [3] noted that TNF-TNFR1-TRADD-TRAF2-RIP-TAK1-IKK pathway mediates constitutive NF- B activation and proliferation in human head and neck squamous cell carcinoma. He also reported that the treatment of HNSCC cells with anti-TNF antibody down regulated constitutively that pathway, making TNF a novel target in the treatment of head and neck cancer. Jaeckel et al. [4] suggested a supportive role of COX-2 in development and progression of HNSCCA. In addition, he emphasized a potential role for selective COX-2 inhibitors in the treatment of these lesions.
Tumors may present like inflammatory lesions, the most common example is inflammatory breast cancer. In English literature, there is a little evidence that head and neck cancers may mimic abscess or inflammation lesion. Barahimi et al. [5] reported a case of prostate cancer metastatic to the orbit that was initially misdiagnosed as orbital cellulites with a subperiosteal abscess. Mavili et al. [6] reported a case of lingual metastasis from a primary lung Adenocarcinoma that mimicking an abscess. Koktekir et al. [7] also reported a case of lung Adenocarcinoma metastasis to frontal sinus that mimic a Pott's puffy tumor. Rutt et al. [8] reported a case of midline carcinoma that presented like tonsillitis in an eight-year-old girl. Chen et al. [9] reported a leukemoid reaction produced by multiple cytokine production in metastatic mucoepidermoid carcinoma with central necrosis.

Also there are multiple articles in world literature indicate that anti-inflammatory medications may suppress the growth of head and neck SCC. Hao et al. [10] mentioned that salvianolic acid B may inhibit the growth of head and neck squamous cell carcinoma in vitro and in vivo via cyclooxygenase- 2 and apoptotic pathways. Jia-Jun et al. [11] reported that nimesulide may inhabit the growth of hypopharyngeal carcinoma cells via suppressing surviving expression. Zhu et al. [12] also noticed that synthetic curcumin analog EF31 inhibits the growth of head and neck squamous cell carcinomaxeno grafts. Qian et al. [13] reported that combined cetuximab and celecoxib treatment may exhibit a synergistic anticancer effect on human oral squamous cell carcinoma in vitro and in vivo.

\section{Conclusion}

Experimental studies about head and neck carcinogenesis, reported clinical cases about head and neck cancer mimicking inflammation lesions, and articles demonstrating tumor suppression by anti-inflammatory medications supported that inflammation may have a role in head and neck carcinogenesis. 
We encourage physicians to aspirate the abscess instead of incision and drainage first if there is a clinical evidence of cancer and wait for the histopathologic and bacterial results; also we encourage them to try anti-inflammtory medications as adjuvant therapy with any head and neck SCC presenting as an inflammatory lesion.

\section{References}

1. Ondrey FG, Dong G, Sunwoo J, Chen Z, Wolf JS, et al. (1999) Constitutive activation of transcription factors NF-(kappa)B, AP-1, and NF-IL6 in human head and neck squamous cell carcinoma cell lines that express pro-inflammatory and pro-angiogenic cytokines. Mol Carcinog 26(2): 119-129.

2. Bancroft CC, Chen Z, Dong G, Sunwoo JB, Yeh N, et al. (2001) Coexpression of proangiogenic factors IL-8 and VEGF by human head and necksquamous cell carcinoma involves coactivation by MEK-MAPK and IKK-NF-kappaBsignal pathways. Clin Cancer Res 7(2): 435-442.

3. Jackson-Bernitsas DG, Ichikawa H, Takada Y, Myers JN, Lin XL, et al. (2007) Evidence that TNF-TNFR1-TRADD-TRAF2-RIP-TAK1IKKpathway mediates constitutive NF-kappaB activation and proliferation in humanhead and neck squamous cell carcinoma. Oncogene 26(10): 1385-1397.

4. Jaeckel EC, Raja S, Tan J, Das SK, Dey SK, et al. (2001) Correlation of expression of cyclooxygenase-2, vascular endothelial growthfactor, and peroxisome proliferator-activated receptor delta with head and necksquamous cell carcinoma. Arch Otolaryngol Head Neck Surg 127(10): 1253-1259.

5. Barahimi B, Patel A, Bilyk JR (2010) Orbital metastasis mimicking subperiosteal abscess. Orbit 29(3): 165-167.
6. Mavili E, Oztürk M, Yücel T, Yüce I, Cağli S (2010) Tongue metastasis mimicking an abscess. Diagn Interv Radiol 16(1): 27-29.

7. Koktekir E, Koktekir BE, Recber F, Akdemir G (2013) Lung Adenocarcinoma metastasis to frontal sinus mimicking Pott's puffy tumor. J Craniofac Surg 24(6): e538-e539.

8. Rutt AL, Poulik J, Siddiqui AH, Konski A, Kalaf M, et al. (2011) NUT midline carcinoma mimicking tonsillitis in an eight-year-old girl. Ann Otol Rhinol Laryngol 120(8): 546-549.

9. Chen YM, Whang-Peng J, Liu JM, Chao Y, Lai CR, et al. (1995) Leukemoid reaction resulting from multiple cytokine production in metastatic Mucoepidermoid carcinoma with central necrosis. Jpn J Clin Oncol 25(4): 168-172.

10. Hao Y, Xie T, Korotcov A, Zhou Y, Pang X, et al. (2009) Salvianolic acid $B$ inhibits growth of head and neck squamouscell carcinoma in vitro and in vivo via cyclooxygenase- 2 and apoptotic pathways. Int J Cancer 124(9): 2200-2209.

11. Jia-Jun T, Su-Mei L, Liang Y, Ju-Ke M, Ya-Kui M, et al. (2012) Nimesulide inhibited the growth of hypopharyngeal carcinoma cells via suppressing Survivinexpression. Head Neck Oncol 4: 7.

12.Zhu S, Moore TW, Lin X, Morii N, Mancini A, et al. (2012) Synthetic curcumin analog EF31 inhibits the growth of head and neck squamous cell carcinoma xenografts. Integr Biol (Camb) 4(6): 633-640.

13. Qian M, Qian D, Jing H, Li Y, Ma C, et al. (2014) Combined cetuximab and celecoxibtreatment exhibits a synergistic anticancer effect on human oral squamous cellcarcinoma in vitro and in vivo. Oncol Rep 32(4): 1681-1688.

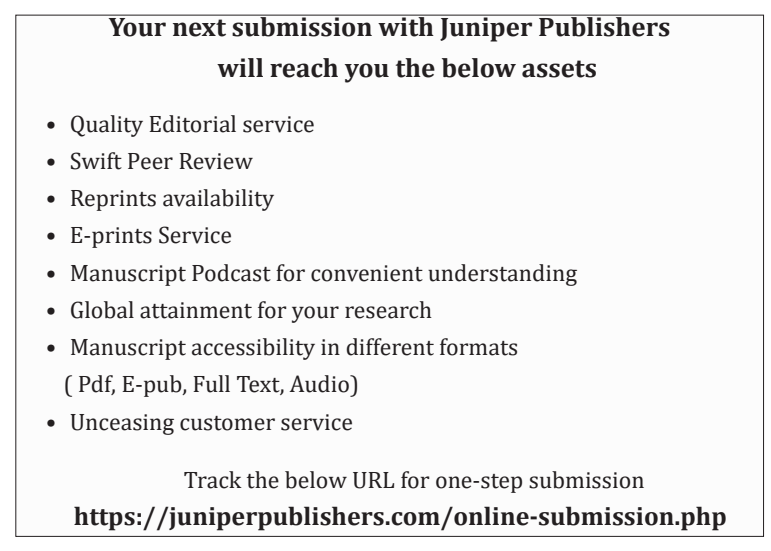

